\title{
Impact of home blood glucose monitoring on childhood diabetes
}

\author{
J H BAUMER, A D EDELSTEN, B C HOWLETT, CAROLINE OWENS, C A PENNOCK, \\ AND D C L SAVAGE
}

Department of Child Health, Bristol University

SUMmARY Ninety diabetic children each provided at least one 24-hour blood glucose profile at home using an impregnated filter paper strip. The mean 24-hour blood glucose level correlated significantly with urine control, height velocity, and $\mathrm{Hb} \mathrm{A}_{1}$. The correlation coefficient for individual blood glucose values $(r=0.61)$ and for mean 24-hour blood glucose values $(r=0.73)$ repeated within 14 days showed an acceptable degree of reproducibility for the blood glucose profiles. Mean 24-hour blood glucose values fell significantly overall $(11.4$ to $9.8 \mathrm{mmol} / \mathrm{l} ; 205$ to $176 \mathrm{mg} / 100 \mathrm{ml})$ in 47 children who had repeated profiles more than 2 weeks apart. Unrecognised nocturnal hypoglycaemia $(<3.0 \mathrm{mmol} / 1 ; 54 \mathrm{mg} / 100 \mathrm{ml})$ was found in $19 \%$ of children on twice-daily Semitard insulin. The study shows that children over age 7 years manage home blood glucose monitoring without difficulty. It shows that the results are reproducible and correlate with other indices of control, and that it provides a practical basis for the improvement of diabetic control.

Conventional methods of assessing diabetic control are notoriously misleading. ${ }^{1}$ Glycosylated haemoglobin $\left(\mathrm{Hb} \mathrm{A}_{1}\right)$ measurement however appears to give a good assessment of medium-term diabetic control, ${ }^{2}$ but provides no information on the times of day when blood glucose is abnormally high or low; it thus offers no practical help in improving control. The recent introduction of reflectance meters and reagent strips has enabled patients to monitor their blood glucose levels, and although this has resulted in improved diabetic control in adults, ${ }^{\mathbf{3} 4}$ the value of home blood-glucose monitoring in children remains unknown. ${ }^{56}$ We have therefore, investigated 24-hour blood glucose profiles using capillary blood samples obtained by children at home and collected on strips of filter paper. We have examined the correlation between these blood glucose profiles and other measurements of diabetic control, the reproducibility of the results, and the impact of blood glucose profiles on diabetic control.

\section{Method}

The clinic comprises 159 diabetic children and adolescents. Ninety-six $(67 \%)$ of the 144 children aged over 7 years have each provided at least one blood glucose profile during the last year. The children were asked to impregnate filter paper (Whatman No 4619 saturated with $5 \%$ boric acid and then dried) with capillary blood obtained by fingerprick using either an Autolet (Owen Mumford) or a Monolet (Sherwood Medical). The samples were obtained on a day (generally at a weekend) with less than $2 \%$ glycosuria on the morning urine specimen at the following times: immediately before and 2 hours after breakfast, lunch and tea, at the child's bedtime, and at $\mathbf{0 3 0 0}$ hours. Only days on which at least five of the eight samples contained adequate amounts of blood for analysis were used for assessment. Few children refused to take part. Six children who provided inadequate amounts of blood were excluded, leaving 90 children for analysis. Two hundred and sixty-four (17\%) of 1509 blood samples provided by these 90 children were too small for reliable analysis. Throughout the period of study the great majority were on Monocomponent (Novo) insulins. Seventy-six ( $84 \%$ ) of the 90 children were on twice daily insulin injections at the time of the first blood profile. The dried filter papers were marked with the patient's name and the date and times of sampling, and posted to the laboratory. Blood glucose level was measured by a glucose oxidase method on an eluate of each spot taken from a punched disc $6 \mathrm{~mm}$ in diameter as described by Wakelin et al., ${ }^{7}$ except that sulphonated 2-4dichlorophenol was used as redox indicator. All blood samples were processed within 2 weeks of being obtained, although blood glucose estimates 
remain reliable for up to 5 weeks (unpublished data). The cost of each capillary blood glucose estimation is about $11 \mathrm{p}, 10 \mathrm{p}$ of which is the cost of technician time.

Glycosylated haemoglobin $\left(\mathrm{Hb} \mathrm{A}_{1}\right)$ was measured by the manual colorimetric method described by Flückiger et al. ${ }^{8}$ The mean of the eight blood glucose values during the 24-hour period, the ' $M$ ' value as described by Schlichtkrull et al., ${ }^{9}$ and the mean of the four fasting specimens (before breakfast, lunch, and tea, and at 0300 hours) were calculated. These values were compared with standard twice daily home 5-drop urine Clinitest results during the preceding 3 months, the height velocity ${ }^{10}$ during the previous year (children with height velocity on or below the 3rd centile were compared with children whose height velocity was above the 3rd centile), and the $\mathrm{Hb} \mathrm{A}_{1}$, provided this had been done within 2 months of the blood glucose estimations. Diabetic control as assessed by urine Clinitest results was considered to be good if at least half the tests were negative and fewer than $20 \%$ contained $2 \%$ glycosuria; otherwise control was considered to be poor.

The reproducibility of the 24-hour blood glucose profile was assessed in children in whom profiles were repeated within 14 days with no change in treatment. Blood samples obtained at the same time of day to within 30 minutes were compared, and a correlation coefficient (r) obtained. The mean 24hour blood glucose values on the 2 days were similarly compared.

In children who had had blood glucose profiles repeated more than 2 weeks apart, the first profile was compared with the last to see if there had been an improvement in the mean blood glucose level with alterations in treatment.

\section{Results}

The blood glucose profiles on the 90 children are shown in Fig. 1. The blood glucose levels after breakfast were the highest overall, while those at

Table Correlations of mean blood glucose levels in 90 children according to urine control and height velocity

\begin{tabular}{lll}
\hline & $\begin{array}{l}\text { Mean 24-hour } \\
\text { blood glucose } \\
(\mathrm{mmol} / \mathrm{l})\end{array}$ & $\begin{array}{l}\text { No of } \\
\text { children }\end{array}$ \\
\hline Urine control good & $9 \cdot 3$ & 24 \\
Urine control poor & $11 \cdot 6^{*}$ & 66 \\
Height velocity $>$ 3rd centile & $10 \cdot 1$ & 52 \\
Height velocity $<3$ 3rd centile & $12 \cdot 1^{* *}$ & 38 \\
\hline
\end{tabular}

$\left.\begin{array}{l}\text { *P<0.02 } \\ \text { **P}<0.03\end{array}\right\}$ Mann Whitney U-test

Conversion: SI to traditional units $-1 \mathrm{mmol} / 1 \approx 18 \mathrm{mg} / 100 \mathrm{ml}$.

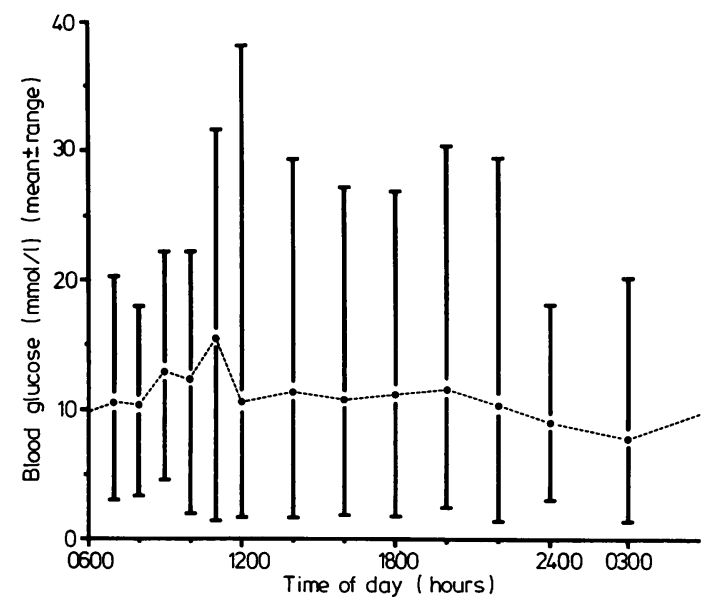

Fig. 1 Mean and range of blood glucose levels during 24 hours in 90 children.

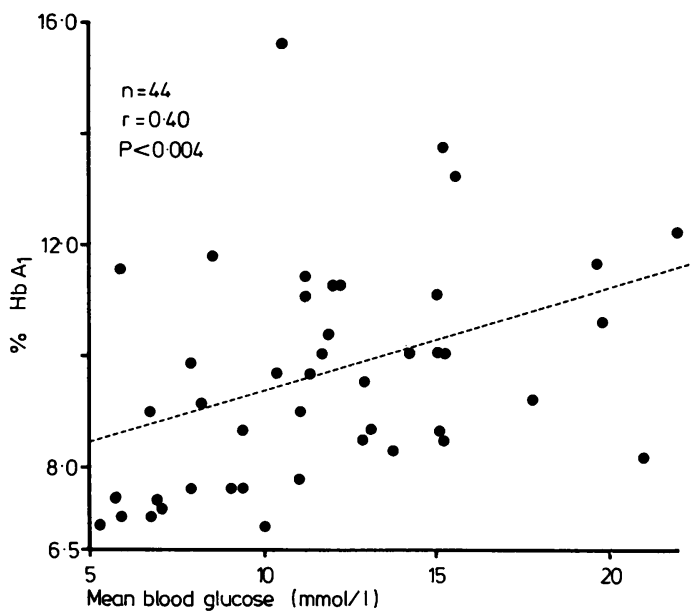

Fig. 2 Relationship between $\mathrm{Hb} \mathrm{A}_{1}$ and mean blood glucose concentration in 44 children.

0300 hours were the lowest. The mean 24-hour blood glucose value for each child was significantly correlated to urine control and height velocity (Table). However, there was a wide scatter of results. There was a significant correlation between mean blood glucose level and $\mathrm{Hb} \mathrm{A}_{1}$ values (Fig. 2, $\mathrm{r}=\mathbf{0 . 4 0}$, $P<0.004)$. ' $M$ ' values correlated no better than mean blood glucose values with urine control, height velocity, and $\mathrm{Hb} \mathrm{A}_{\mathbf{1}}$. There was no significant correlation between the mean of all the fasting or the initial prebreakfast blood glucose values and urine control, height velocity, or $\mathrm{Hb} \mathrm{A}_{1}$ values. 


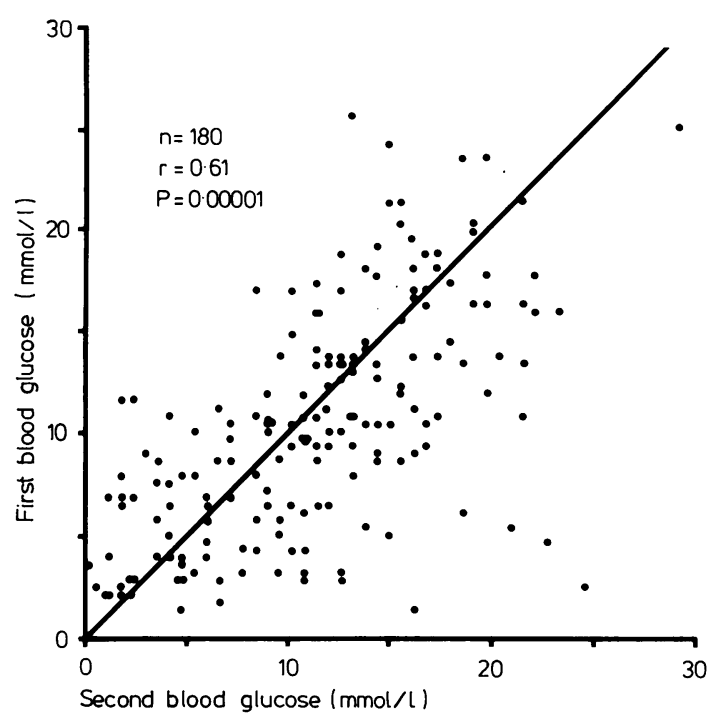

Fig. 3 Reproducibility of individual blood glucose values at similar times within 14 days.

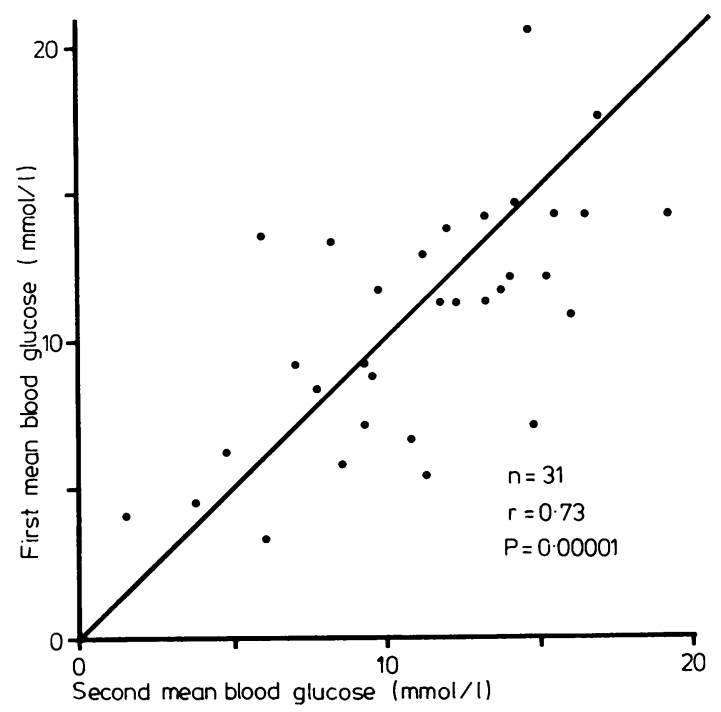

Fig. 4 Reproducibility of mean 24-hour blood glucose values repeated within 14 days.

Fig. 3 shows the reproducibility of 180 pairs of individual blood glucose values on different days within 2 weeks $(r=0 \cdot 61, P=0.00001)$. Fasting blood glucose pairs were not significantly better correlated than postprandial blood glucose pairs. For the 31 children in whom blood glucose profiles were re-

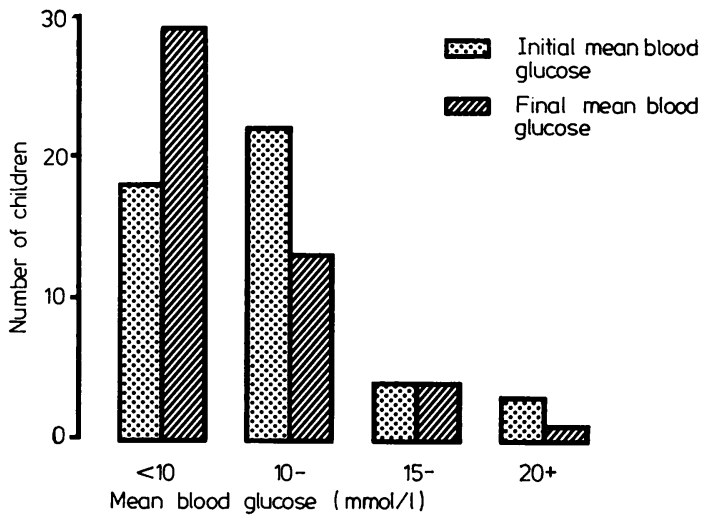

Fig. 5 Effect of change in treatment on mean 24-hour blood glucose values (improvement significant $P<0.05$, Wilcoxon's matched pairs rank test).

peated within 14 days, the two mean blood glucose values correlated closely (Fig. $4, \mathrm{r}=0.73, \mathrm{P}=$ 0.00001).

Forty-seven children had repeated 24-hour blood glucose profiles more than 14 days apart. The average time interval between profiles was $3 \frac{1}{2}$ months. We compared the first and last mean blood glucose values to see if alterations in treatment had appreciably improved control. There was an average reduction of $14.5 \%$ in mean blood glucose (from 11.4 to $9.8 \mathrm{mmol} / \mathrm{l} ; 205$ to $176 \mathrm{mg} / 100 \mathrm{ml}$ ); this was significant using Wilcoxon's matched pairs rank test $(\mathrm{P}<0.05)$. With the children divided into groups according to their initial mean blood glucose level (Fig. 5), improvement had taken place mainly in children with mean blood glucose values between 10 and $15 \mathrm{mmol} / \mathrm{l}(180$ and $270 \mathrm{mg} / 100 \mathrm{ml})$. Control in nearly three times as many children improved as worsened.

We compared the 0300 hour and first morning (0700-0900 hours) blood glucose levels of children on twice daily Actrapid and Semitard insulin with those on twice daily Actrapid and Monotard insulin. There was no significant difference in mean blood glucose ( 11.7 and $12.8 \mathrm{mmol} / 1$ ( 211 and $230 \mathrm{mg} / 100$ ml) respectively) on the first morning specimen. However, the mean 0300 hour blood glucose of children on Semitard insulin was significantly lower than on Monotard insulin $(7.5$ and $9.6 \mathrm{mmol} / \mathbf{1}$ $(135$ and $173 \mathrm{mg} / 100 \mathrm{ml})$ respectively, $\mathbf{P}<0.05$ Mann-Whitney U test); 15 (19\%) of 78 blood glucose values at 0300 hours of children on evening Semitard insulin were $3.0 \mathrm{mmol} / 1(54 \mathrm{mg} / 100 \mathrm{ml})$ or below, compared with $4(10 \%)$ of 40 blood glucose values of children on Monotard insulin. This nocturnal hypoglycaemia had not been recognised by any of 
the children or parents. The mean percentage rise in blood glucose between 0300 hours and the morning was greater in children on Semitard than in those on Monotard insulin $(+119 \%$ and $+55 \%$ respectively, $\mathrm{P}<0.005$ Student's $t$ test).

\section{Discussion}

We found that home-based 24-hour blood glucose profiles could be used without difficulty by most diabetic children over age 7 years. Very few children expected or found the tests unpleasant, and many said they were less tedious than repeated urine testing. Inadequate amounts of blood were obtained more often than in adult diabetics using the same technique.$^{34}$ but sampling improved with practice. In assessing the value of this technique, information is needed on the reproducibility of the results, their correlation with other techniques of monitoring, and whether improvement in diabetic control can be achieved.

We have shown that though there may be appreciable variations between paired capillary blood glucose levels taken on different days, the pattern of the blood glucose profile is sufficiently reproducible to give practical information on which to base changes in treatment. The eight blood glucose values give a reasonably dynamic representation of the blood glucose profile during the 24-hour period. In contrast the conventional standard twice daily urine tests, taken at times of relative fasting, give a brief and unrepresentative picture of the daily level of glycaemia. It is therefore of interest that our data show that it is only when postprandial blood glucose levels are included that the mean blood glucose correlates with other indices of control. In particular there is a highly significant correlation with $\mathrm{Hb} \mathrm{A}_{1}$ which, as we showed previously, ${ }^{11}$ correlates with height velocity and urine glucose estimates.

In an uncontrolled study it is difficult to be sure that the improvement in mean blood glucose is due to any single factor. No fundamental change occurred in the clinic during this period. The clinic continued to be managed by a consultant paediatric endocrinologist with a senior registrar and clinical assistant; the philosophy of continuing education to improve control has persisted throughout. The frequency of clinic visits remained unchanged, although sometimes there was correspondence between visits.

The 24-hour profiles have undoubtedly helped to improve control in a number of children. Six children with apparently good control on urine testing had mean blood glucose values $>12 \mathrm{mmol} / 1 \quad(>216$ $\mathrm{mg} / 100 \mathrm{ml}$ ); some of them subsequently admitted faking their urine tests, and their control improved with suitable discussion and adjustments to diet and insulin dosage. Two-thirds of all the children had periods of hyperglycaemia $(>10 \mathrm{mmol} / \mathrm{l} ;>180$ $\mathrm{mg} / 100 \mathrm{ml}$ ) during the day or night interspersed with normal $(<8 \mathrm{mmol} / \mathrm{l} ;<144 \mathrm{mg} / 100 \mathrm{ml}$ ) blood glucose levels; adjustments to the dose of individual short- or long-acting insulins in many cases improved control. We confirmed the presence of nocturnal hypoglycaemia with hyperglycaemia before breakfast on twice daily Semitard insulin. ${ }^{12} 13$ The fasting morning hyperglycaemia is probably secondary to a morning insulin deficiency.$^{14}$ Many of these children have periods of 16 hours or longer between the afternoon and morning injections of Semitard insulin, the effect of which is waning rapidly after about 12 hours. Increasing the dose of evening Semitard insulin will often accentuate nocturnal hypoglycaemia without altering early morning hyperglycaemia, while conversion to the longer acting Monotard insulin improves control.

There is currently a choice between reflectance meters, reagent strips, and impregnated filter paper strips for home blood glucose monitoring. Reflectance meters are too expensive to supply routinely. Haemoglukotest reagent strips (Boehringer Mannheim) are believed to be reliable in adults, ${ }^{1516}$ and although Ferguson and Prosser ${ }^{17}$ found them to be reliable in 5 children, our experience is that some children find the haemoglukotest strips difficult to interpret. Therefore we check each child's ability to read the reagent strips correctly using simultaneous filter strip assessment before reagent strips are used routinely. ${ }^{18}$

In many cases adjustments to control by the child or parent can be more effective after discussion with the paediatrician. Sometimes this is because of wide variations in the blood glucose levels from day to day, and in a few lack of knowledge and care make them incapable of acting appropriately upon their blood glucose results. Laboratory analysis of impregnated filter paper strips ensures that parents do not insist on blood glucose measurements too frequently, and is fairly immune to attempts at deception (although one teenager attempted to augment her blood sample on the filter paper with red ink). However, in selected families, haemoglukotest reagent strips are undoubtedly useful.

The use of impregnated filter paper strips for home blood glucose monitoring has been examined previously in adults. ${ }^{19}$ This is the first report of its use in children. We are enthusiastic about its potential. The technique is very suitable for semiautomated processing either on an autoanalyser ${ }^{20}$ or a Beckman glucose analyser 2 . The total cost of the manual method of analysis is comparable with that of the haemoglukotest reagent strips (12p each) and 
dextrostix strips (10p each). A semiautomated method might be considerably cheaper. Its cheapness and simplicity means that all diabetic clinics should be able to add it to their methods for assessment of control.

Our results clearly demonstrate that in compliant families home blood glucose monitoring significantly improves diabetic control. In the expectation that their long-term complications will be reduced, we believe that all children with diabetes should have the benefit of home blood glucose monitoring.

C O was supported by a grant from Novo Laboratories Limited, Basingstoke.

\section{References}

1 Malone J I, Hellrung J M, Malphus E W, Rosenbloom A L, Grgic A, Weber F T. Good diabetic control-a study in mass delusion. $J$ Pediatr 1976; 88: 943-7.

2 Koenig R J, Peterson C M, Jones R L, Saudek C, Lehrman M, Cerami A. Correlation of glucose regulation and hemoglobin $\mathrm{A}_{\mathrm{lc}}$ in diabetes mellitus. $N$ Engl $\mathrm{J}$ Med 1976; 295: 417-20.

3 Sönksen P H, Judd S L, Lowy C. Home monitoring of blood-glucose; method for improving diabetic control. Lancet 1978 ; i: 729-32.

4 Walford S, Gale E A M, Allison S P, Tattersall R B. Self-monitoring of blood-glucose; improvement of diabetic control. Lancet 1978; i: 732-5.

5 Steel J M, Cramb R, Duncan L J P. How useful are patient-operated blood glucose meters? Practitioner 1980; 224: $651-3$

6 Anonymous. Home blood-glucose monitoring: revolution, revelation, or rip-off ? Lancet 1980 ; ii: 187-8.

7 Wakelin K, Goldie D J, Hartog M, Robinson A P. Measurement of capillary blood glucose in filter-paper spots: an aid to the assessment of diabetic control. $\mathrm{Br}$ Med J 1978; ii: 468-9.

8 Flückiger R, Berger W, Winterhalter K H. Haemoglobin
$A_{\text {lc }}$, a reliable index of diabetic control (abstract). Diabetologia 1977; 13: 393.

9 Schlichtkrull J, Munck O, Jersild M. The M-value, an index of blood-sugar control in diabetics. Acta Med Scand 1965; 177: 95-102.

10 Tanner J M, Whitehouse R H. Height and weight charts 1975. Obtainable from Creaseys of Hertford Limited, Castlemead, Hertford SG14 1LH.

11 Williams M L, Savage D C L. Glycosylated haemoglobin levels in children with diabetes mellitus. Arch Dis Child 1979 ; 54 : 295-8.

12 Gale E A M, Tattersall R B. Unrecognised nocturnal hypoglycaemia in insulin-treated diabetics. Lancet 1979; i: $1049-52$.

13 Werther G A, Jenkins P A, Turner R C, Baum J D. Twenty-four-hour metabolic profiles in diabetic children receiving insulin injections once or twice daily. $\mathrm{Br} \mathrm{Med} \mathrm{J}$ 1980; 281 : 414-8.

14 Gale E A M, Kurtz A B, Tattersall R B. In search of the Somogyi effect. Lancet 1980; ii : 279-82.

15 Walford S, Clarke P, Paisey R, Hartog M, Allison S P. Letter: Home blood-glucose measurements without reflectance meter. Lancet 1980 ; i: $653-4$.

16 Earis J E, Greenway M W, Macaulay M B. Blood glucose monitoring without a meter. Lancet 1980 ; i: 823-4.

17 Ferguson S D, Prosser R. Are reflectance meters necessary for home blood glucose monitoring? $\mathrm{Br} \mathrm{Med} \mathrm{J}$ $1980 ; 281$ : 912

18 Baumer J H, Savage D C L. Letter: Are reflectance meters necessary for home blood glucose monitoring? Br Med J 1980; 281 : 1286.

19 Paisey R, Bradshaw P, Hartog M, West P. Letter: Home monitoring of blood glucose using filter paper strips. $\mathrm{Br}$ Med J 1979; ii: 1509.

20 West P, Marsland I, Bradshaw P. Automated capillary blood spot glucose estimation. Med Lab Sci 1979; 36: 379-80.

Correspondence to Dr J H Baumer, Department of Child Health, Royal Hospital for Sick Children, St Michael's Hill, Bristol BS2 8BJ.

Received 1 May 1981 